№ 1 (1), 2021

\title{
ФУНКЦІОНАЛЬНА ДІАГНОСТИКА СТАНУ СЕРЦЕВО-СУДИННОЇ СИСТЕМИ В КОНТЕКСТІ СУЧАСНИХ ІНФОРМАЦЙНИХ СИСТЕМ
}

\author{
3. Микитюк, Г. Барило, О. Блавт, І. Кремер, Ю. Кочурак \\ Національний університет “Львівська політехніка”, вул. С. Бандери, 12, Львів, 79013, Україна
}

Відповідальний за рукопис: О. Блавт (e-mail: oksanablavt@ukr.net).

(Подано 28 травня 2021)

\begin{abstract}
Стаття висвітлює проблему забезпечення якості та достовірності функціональної діагностики стану серцево-судинної системи на основі контролю частоти серцевих скорочень. Викладено новий підхід до реалізації діагностичних процедур у режимі реального часу із застосуванням сучасних інформаційних систем, якимй уможливлюе істотне підвищення їхньої ефективності. Запропоновано багатоканальну систему реєстрації частоти серцевих скорочень, призначену для неперервного вимірювання пульсу в режимі реального часу. Передбачено використання в складі багатоканальної системи сучасного інформаційного комплексу засобів електронно-обчислювальної техніки, що не тільки забезпечує отримання кількісних значень окремих параметрів, а й дає змогу вирішити широке коло діагностичних завдань під час дослідження серцево-судинної системи із високим рівнем достовірності. Обгрунтовано, що цим забезпечується усунення низки проблемних чинників процесу діагностики на основі технології інтегрування множинних функцій у єдину багатоканальну систему, що дає змогу підвищити ефективність процесу функціональної діагностики серцево-судинної системи, іiі оперативність та якість.
\end{abstract}

Ключові слова: діагностика; сериево-судинна система; частота сериевих скорочень; багатоканальна система.

УДК: 004.65:616-072.7:611.1

\section{1. Ветуп}

Функціональна діагностика стану серцево-судинної системи (ССС) є одним із перших та ключових етапів сучасних алгоритмів діагностичних процедур у клінічних дослідженнях галузі лікувальної та спортивної медицини, фізичної культури та спорту. Реалізується така діагностика за показниками частоти серцевих скорочень (ЧСС), яка $є$ важливим параметром функціональної активності ССС та стану органів кровообігу загалом. Показники ЧСС як корелятора фізіологічних реакцій ССС доступні та зручні для експрес-контролю роботи серця, а також визначення реакції організму на фізичне навантаження, дослідження фізичної працездатності, емоційних напружень тощо [1].

Поліпшення якості діагностики стану ССС, розроблення нових методів і способів дослідження для визначення та оцінювання функціонального стану серцевого ритму, визначення толерантності (здатності) до фізичного навантаження у здорових осіб, як можливості отримання інформації щодо діяльності ССС, актуальні [2-4]. Сучасний прогрес у використанні електронних методів у вимірювальних засобах, системах та пристроях діагностики функціональних систем організму створює можливість модернізації та ідентифікації засобів контролю ЧСС задля по-

๑) 2021 Національний університет “Львівська політехніка” 
ліпшення їх інформаційного забезпечення, a відтак забезпечення отримання достовірних результатів діагностичних процедур.

\section{2. Аналіз та постановка задачі}

До проблеми розвитку інформаційних систем контролю ЧСС та діагностики ССС зверталося чимало авторів [5-8]. У наукових дослідженнях [1, 9, 10] розглянуто методи інструментальної діагностики: електрокардіографію, різновиди пульсометрії (сфігмографію, плетизмографію) тощо, які є найпоширенішими методами контролю стану ЧСС, а через неї - й інших органів і систем організму. Частково вирішити це питання можна, використовуючи комерційно доступні пристрої. Серед таких годинник-пульсометр, сенсор пульсу на нагрудному ремені, ручний датчик, електронні монітори серцевого ритму Polar тощо. Однак загальним недоліком перелічених вище приладів є їхні технічні можливості, що мають суттєві обмеження і не задовольняють повною мірою потреби функціональної діагностики. Зокрема низька оперативність досліджень та обмеженість каналів реєстрації сигналів не дають змоги визначати у режимі реального часу (real time) ЧСС кількох осіб одночасно.

Однак дослідження багатьох функціональних показників ССС не завжди достатньо інформативне в стані відносного фізіологічного спокою. Суть функціональної діагностики полягає ще і в аналізі механізмів, які зумовлюють зміни в функціонуванні ССС під впливом різних чинників [3]. Саме тому, щоб об' єктивно і достовірно оцінити функціональні можливості ССС за показниками ЧСС, вивчають іï реакцію на будь-який вплив. 3 цією метою під час функціонального обстеження використовують функціональні проби або тести (гарвадський степ-тест, пробу Мартіне-Кушелевського тощо) [1, 7].

Звернемо увагу на особливості реєстрації ЧСС під час проведення функціональних проб. Для того, щоб вивчити реакцію ЧСС, іï підраховують не за одну хвилину, а за коротші інтервали часу, найчастіше це 10,15 або 30 секунд, коли об'єкт дослідження перебуває у русі, отримуючи навантаження. Навантаження можна використовувати для оцінювання функціонального стану ССС 3 огляду на те, що це фізіологічний стрес, що сприяє виявленню порушень з боку ССС, які не можна виявити в стані спокою. Оцінка толерантності до навантаження здійснюється не тільки у разі патологій ССС, але і у різних контингентів здорових людей: військових, спортсменів, осіб, які за родом діяльності зазнають фізичних навантажень $[1,6]$.

Отож, використання вищеперелічених засобів не дає змоги зреалізувати діагностику ССС в умовах активної життєдіяльності організму суб'єкта контролю. Технічні труднощі, які супроводжують використання тестових методик, унеможливлюють діагностику ЧСС та виявлення його змін в умовах навантажувальної функціональної активності.

\section{3. Формулювання цілі статті}

Метою статті є розроблення технічних засобів для здійснення функціональної діагностики стану ССС із використанням багатоканальних інформаційних систем безпровідного зв’ язку.

\section{4. Реалізація функціональної діагностики ССС 3 використанням автоматизованих ресструвальних засобів}

Наше дослідження спрямовано на усунення низки проблемних чинників у процесі реалізації функціональної діагностики ССС із використанням автоматизованих реєструвальних засобів. Основна ідея полягає в інтенсифікації діагностичного процесу, що істотно підвищує його інформаційні можливості. Результати здійсненого наукового пошуку втілено у 
багатоканальній системі реєстрації ЧСС, яка призначена для неперервної діагностики стану ЧСС особи чи групи осіб.

Для забезпечення безпровідного зв’язку декількох індивідуальних пристроїв вимірювання ЧСС та передавання інформації у ПК розроблено оригінальний багатоканальний радіочастотний модем на 16 каналів (за необхідності кількість каналів можна збільшити до 64). Максимальна відстань між передавальними модулями, розміщеними на суб'єкті контролю, та приймальним модулем, що передає сигнали у ПК, становить 500 м.

Структурну схему розробленої багатоканальної системи із радіочастотним зв'язком для контролю ЧСС наведено на рис. 1. Як сенсори ЧСС використано багатофункціональний гібридний годинник Reebok Hybrid Plus (1), пасковий пульсометр компанії Polar (2), оптичний пульсометр (3). Сигнали 3 цих сенсорів надходять на Bluetooth приймач (4) і через інтерфейсний мікропроцесор (5) 3'єднуються із радіочастотними передавачами (6). Переданий радіочастотний сигнал фіксує приймач (7) i через відповідний інтерфейсний мікропроцесор він надходить на персональний комп'ютер для подальшого аналізу та відображення. Візуалізацію результатів контролю ЧСС забезпечує програмне забезпечення, в якому задають номер каналу приймання-передавання, час діагностики, критичні межі ЧСС тощо.

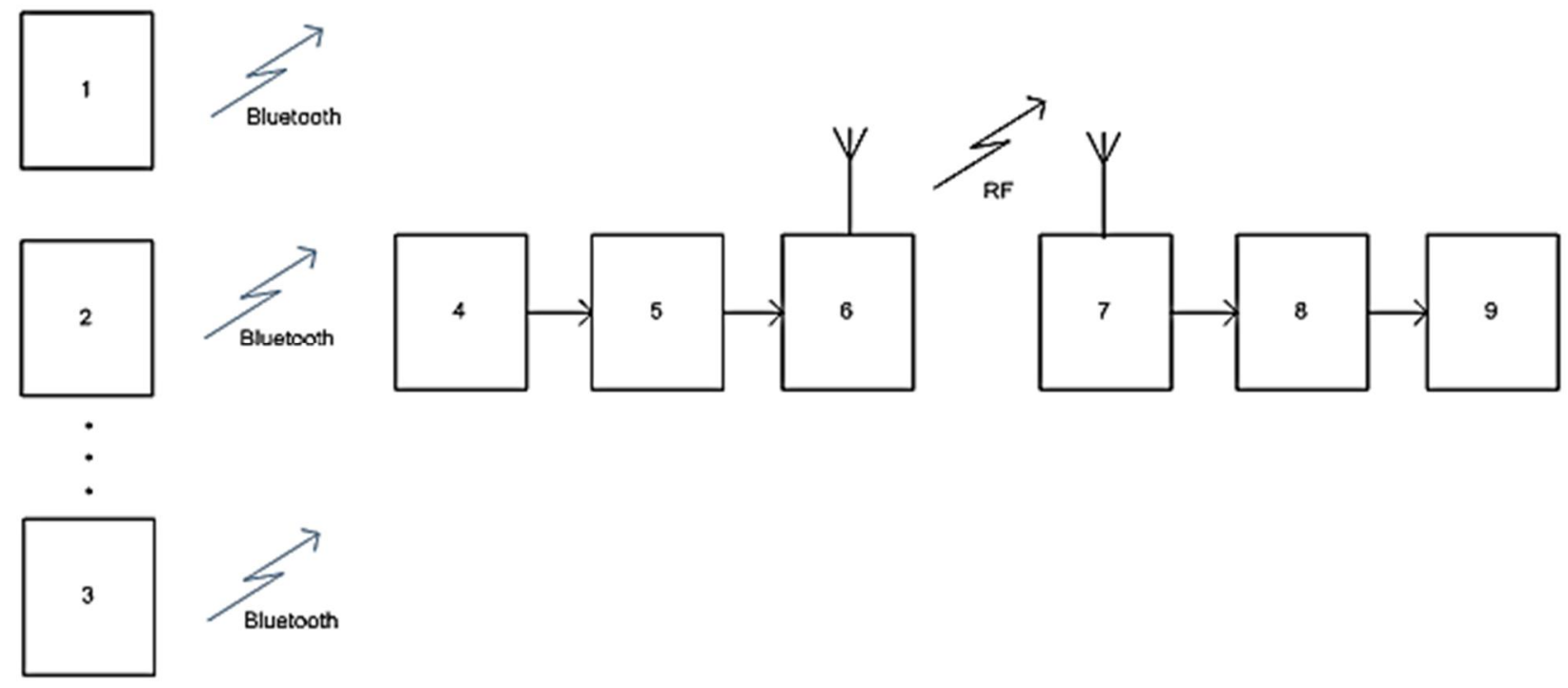

Рис. 1. Структурна схема системи

Канал радіозв'язку реалізовано на новому поколінні пристроїв для передавання і приймання сигналу - мікроелектронних трансиверах TR3000 [11]. Такі трансивери задовольняють вимоги сучасних пристроїв wireless-комунікації (можливість бездротового обміну інформацією між пристроями). Це дає змогу зробити безпровідну мережу розгорнутішою, використовуючи декілька точок доступу, і не потрібно з'єднувати їх за допомогою дротів. Відповідно до стандарту ISM (Industrial, Scientific, Medical) ïх широко застосовують для радіозв' язку в сертифікованому діапазоні частот. Робочі частоти передавання інформації містяться у діапазоні 433,72-434,12 МГц, що забезпечує високу пропускну здатність - до 115 кбіт/с.

Трансивер TR3000 є функціонально завершеним приймачем. У разі зниження глибини модуляції та роботи в безперервному режимі ASK (Amplitude Shift Keying) швидкість передавання даних зростає до 115,2 кБод. Принципово важливі переваги використаних у розробці трансиверів TR3000 такі:

- $\quad$ доволі велика дальність передавання (до 500 м);

- малі габарити (декілька сантиметрів); 
- низький рівень електромагнітного випромінювання: вихідна потужність не перевищує 2 мВт, що дає змогу розмістити передавач безпосередньо на тілі людини;

- забезпечення нормальної роботи із низьковольтними джерелами живлення $(2,7 \div 3,5$ B);

- $\quad$ наявність режиму очікування (sleep mode), в якому схема практично не споживає енергії (струм споживання у режимі очікування не перевищує 5 мкА), що дає змогу використовувати малогабаритні гальванічні елементи живлення (оптимально - два елементи типу ААA).

Висока завадостійкість радіочастотного зв'язку забезпечується цифровим кодуванням сигналу, в передавачі використана інтегральна схема кодера MC145026 (Motorola), а в приймачі декодера МC145028. Активний сигнал на виході декодера 3'являється тільки у разі збігу кодової комбінації на виводах 1-5 кодера та декодера. В такий спосіб отримують доволі значну кількість комбінацій кодування, що уможливлює використання одного частотного каналу для контролю багатьох осіб одночасно.

Функціональну схему трансивера наведено на рис. 2. Схема містить радіочастотні підсилювачі, детектори, систему фазового автоматичного підстроювання частоти, систему автоматичного регулювання підсилення, ідентифікатори рівня демодульованого сигналу, фільтри. Висока якість сигнального перетворення забезпечена використанням функціональної електроніки, зокрема пристроїв на поверхнево-акустичних хвилях [12]. Всі ці компоненти інтегровані в малогабаритну гібридну мікрозбірку.

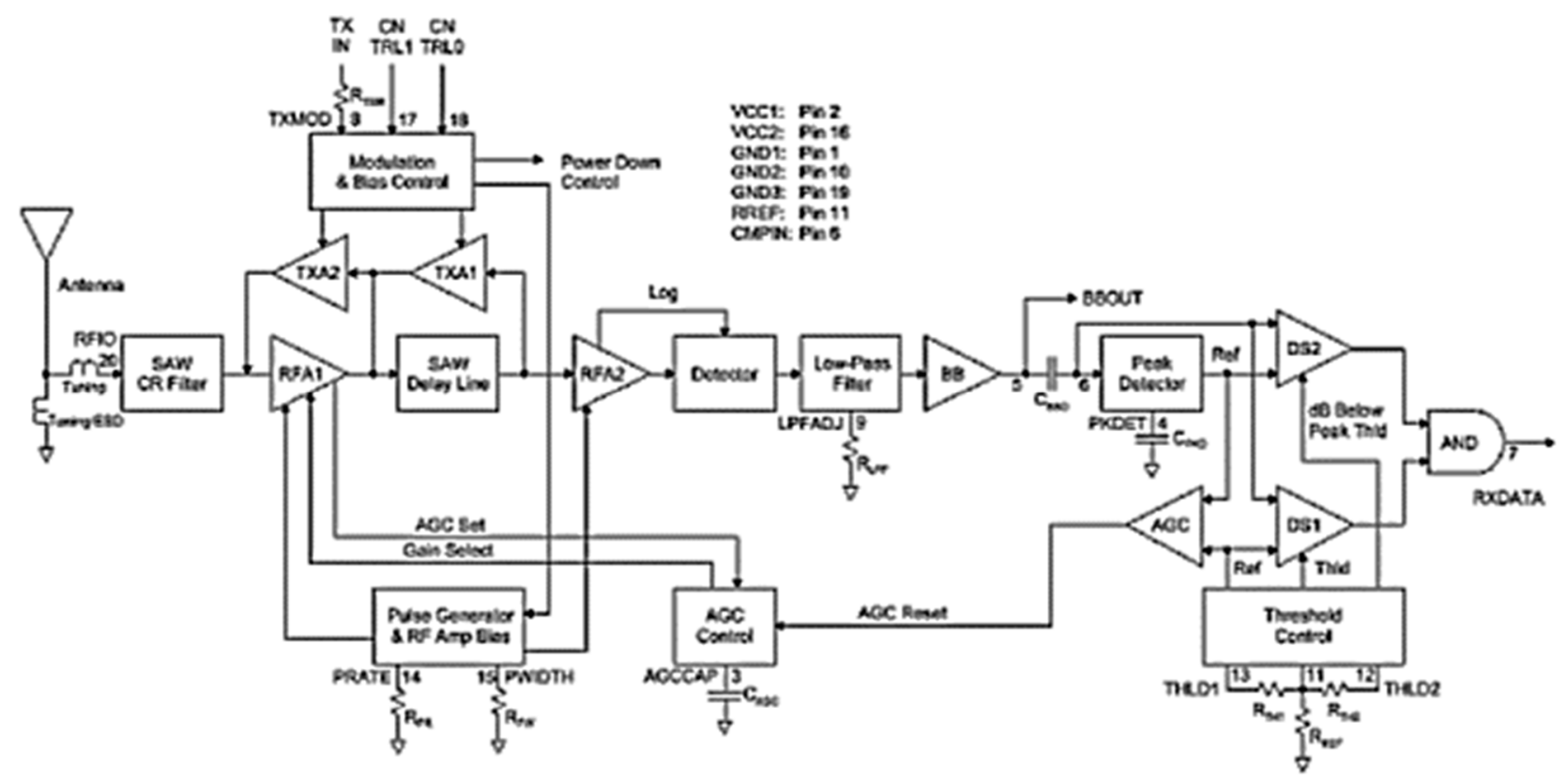

Рис. 2. Функиіональна схема трансивера

У пристрої трансивери з'єднуються із системою вимірювання ЧСС та ПК за допомогою мікроконтролерів, які забезпечують кодування-декодування інформації та інтерфейсну сумісність. Під час радіопередавання цифрових імпульсів принципово важливим $\epsilon$ використання спеціальних методів модуляції, зокрема кодування манчестерським кодом чи NRZ (Non-Return to Zero), в якому одиничні біти кодуються додатними, а нульові біти - від'ємними імпульсами.

Для керування трансиверами та інтерфейсами передавання даних використано поширений мікроконтролер C8051F231 на основі ядра 8051. У цього мікроконтролера широка внутрішня архітектура (рис. 3) та великий набір команд, що дає змогу максимально ефективно використовувати ресурси трансиверів та забезпечити високу швидкість обміну інформацією. 


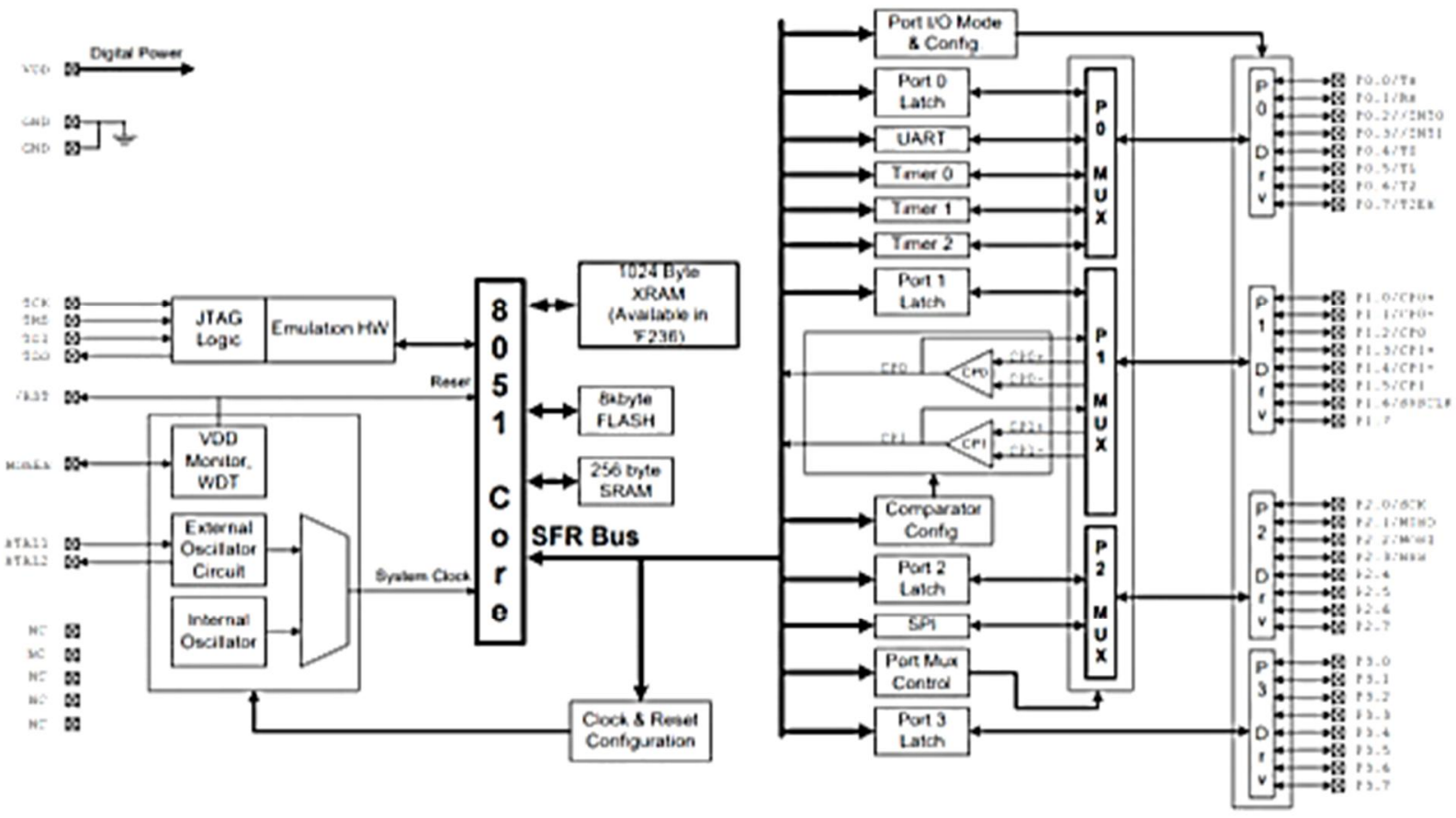

Рис. 3. Внутрішня архітектура мікроконтролера

Трансивер, мікроконтролер, гальванічні джерела живлення та антени об'єднуються у передавальні та приймальні модулі [13]. Типову схему модуля наведено на рис. 4.

Антени реалізовано у вигляді чвертьхвильових вібраторів. Антена передавача розміщена безпосередньо в корпусі передавального модуля, а це істотно покращує його ергономічні параметри та визначає їі тактико-технічні можливості. Антену приймача винесено за корпус приймального модуля, що підвищує чутливість, а отже, дальність приймання.

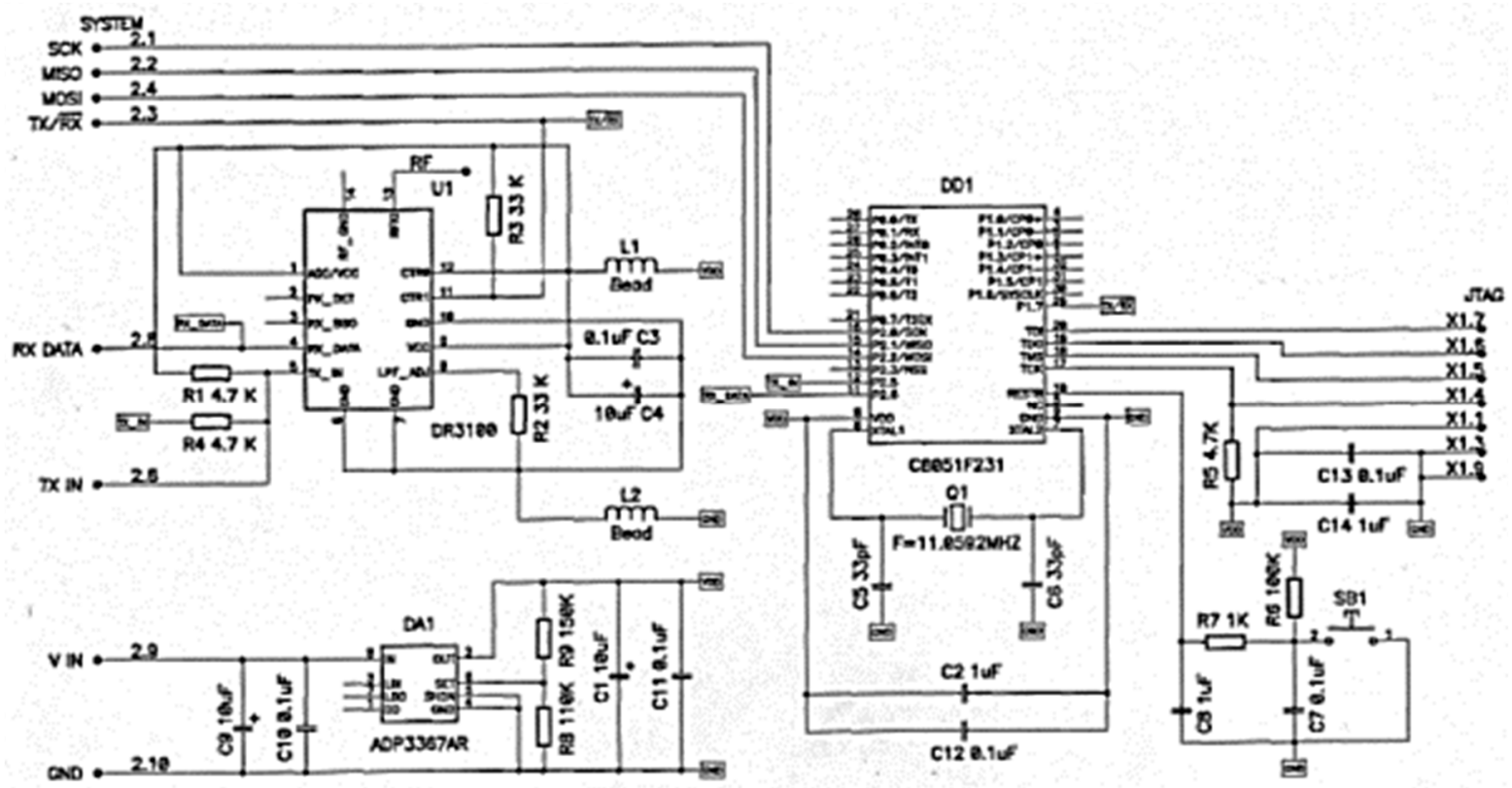

Рис. 4. Схема модуля 
Температурний діапазон експлуатації пристрою становить від мінус 40 до плюс $85^{\circ} \mathrm{C}$, що дає змогу використовувати його в будь-яку пору року. Фотографію дослідних зразків передавального (TR \& MC) та приймального (RV \& MC) модулів наведено на рис. 5.

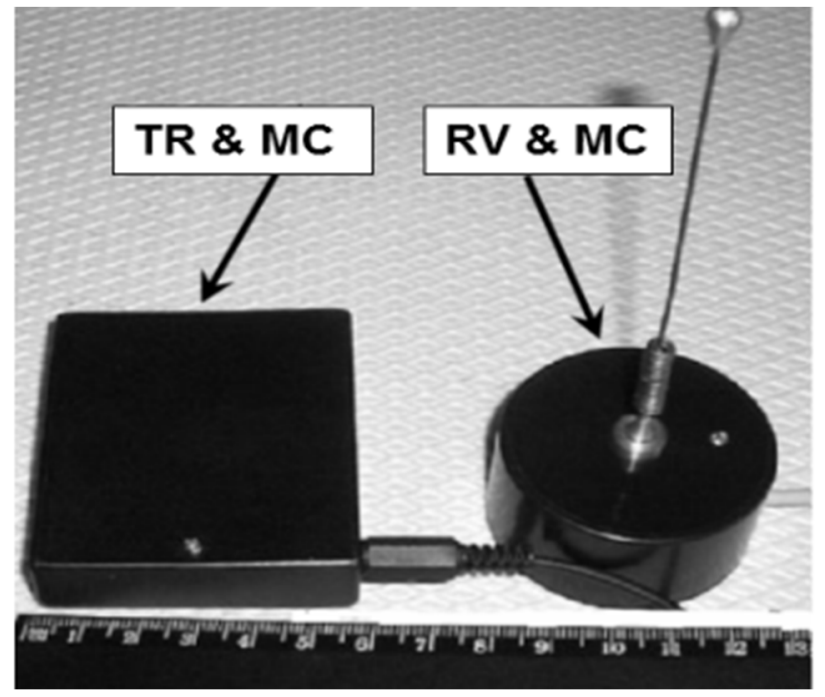

Puc. 5. Дослідні зразки передавального (TR \& MC) та приймального $(R V \& M C)$ модулів

У робочому вікні розробленого програмного забезпечення контролю ЧСС вибирають номер каналу радіозв' язку, режими вимірювання, а також гранично допустимі межі зміни ЧСС. Результат вимірювання відображається у числовій та графічній формах.

Передбачено використання у складі багатоканальної системи сучасного інформаційного комплексу засобів електронно-обчислювальної техніки, яка дасть змогу не тільки отримувати кількісні значення окремих параметрів, а й вирішити широке коло діагностичних завдань у разі застосування до дослідження ССС. Ефективність використання багатоканальної системи діагностики ЧСС забезпечується: зручністю у використанні та компактністю пристрою, комфортністю проведення діагностики, багатофункційністю (широкий спектр застосування), високим рівнем чутливості системи, комплексним підходом: розроблена багатоканальна система уніфікує й інтенсифікує одержання й оброблення результатів діагностики ЧСС із поновленням й коригуванням великого масиву інформації, контролем й накопиченням іiі у інтегрованій базі, у якій налагоджено їхню реплікацію, оброблення та інтерактивний аналіз 3 використанням статистичних та математичних методів й алгоритмів.

Резюмуючи викладене, під час оцінювання можливостей запропонованого методу реєстрації ЧСС керуємось кількома міркуваннями, серед яких найважливіші такі:

- висока точність одержуваних результатів діагностики;

- $\quad$ можливість проведення стандартизованої процедури діагностики, що є чільним чинником ії об'єктивності;

- простота й доступність технічних засобів реалізації діагностики;

- негайне отримання результату;

- наявність алгоритмів розрахунку за даними реєстрації та простота медико-біологічної інтерпретації результатів.

\section{Висновки}

Запропоновано інноваційну концепцію організації діагностичного обстеження функціонального стану ССС. Реалізовано якісно новий підхід до підвищення ефективності діагностичного 
процесу, відповідний стандартам сучасності. Модернізувавши процес функціональної діагностики $\mathrm{CCC}$, ми забезпечуємо його реалізацію на сучасному науковому рівні.

Вперше запропоновано програмне комплексне інформаційно-комунікаційне забезпечення функціональної діагностики стану ССС, яке уніфікує й інтенсифікує отримання й опрацювання результатів, що дає змогу розв'язати задачі оперативної діагностики, негайного отримання та накопичення даних задля одержання об'єктивної інформації про функціональний стан ССС. Розроблену інформаційну систему діагностики стану ЧСС реалізовано у вигляді інтегрованого програмного середовища, що дає можливість реалізувати отримання об'єктивної інформації та накопичення діагностичних даних протягом тривалого часу. Відтак вирішено актуальну науково-прикладну проблему створення системи експрес-діагностики ЧСС у режимі реального часу одномоментно кількох осіб, які перебувають у стані функціональної активності.

Ураховуючи простоту, зручність, доступність та швидкість отримання діагностичних даних, багатоканальну систему реєстрації ЧСС можна рекомендувати використовувати 3 метою забезпечення об' єктивної клінічної діагностики задля раннього скринінгу захворювань ССС, здійснення первинної профілактики, контролю ефективності певних заходів та виявлення можливих ризиків.

\section{Список використаних джерел}

[1] Загальна теорія здоров'я та здоров'язбереження: колективна монографія (2017) / за заг. ред. проф. Ю. Д. Бойчука. Харків: Вид. Рожко С. Г. 488 с.

[2] Li, J. Y., Кио T. B., Hsieh S. S. and al. (2008). "Changes in electroencephalogram and heart rate during treadmill exercise in the rat". Neurosci. Lett, vol. 434, no. 2, pp. 175-178.

[3] MacKenzie, R. (2007). "Nonsustained wide QRS tachycardia during an exercise ECG stress test". Insur. Med., vol. 39, no. 3, pp. 205-213.

[4] Woo E H., White P. and Lai C.W. (2016). Musculoskeletal impact of the use of various types of electronic devices on university students in Hong Kong: An evaluation by means of self-reported questionnaire. Man Ther, vol. 26. pp. 47-53.

[5] Koryahin, V., Mukan, H., Blavt, O. and Virt, V. (2019). "Students' coordination skills testing in physical education: ICT application”. Information Technologies and Learning Tools, vol. 70, no. 2, pp. 216-226. https://doi.org/10.33407/itlt.v70i2/

[6] Lippi, G., Henry, M. B. and Sanchis-Gomar, F. (2020). "Physical activity and cardiovascular disease at the time of coronavirus disease 2019 (COVID-19”). Eur J. Prev Card, vol. 27, no. 9, pp. 906-908.

[7] MacKenzie, R. (2007) "Nonsustained wide QRS tachycardia during an exercise ECG stress test". Insur. Med., vol. 39, no. 3, pp. 205-213.

[8] Woo E. H., White P. and Lai C. W. (2016).Musculoskeletal impact of the use of various types of electronic devices on university students in Hong Kong: An evaluation by means of self-reported questionnaire. Man Ther, vol. 26. pp. 47-53.

[9] Mintser, O. P., Semenets, V. V. and Potiazhenko, M. M. (2020). "The study of the electromagnetic component of the human body as a diagnostic indicator in the examination of patients with Non-communicablediseases: problem statement" Wiadomości Lekarskie, vol. 6, no. 73, pp. 1279-1283.

[10] Casey, D. P., Nichols, W. W. and Braith, R. W. (2008) "Impact of aging on central pressure wave reflection characteristics during exercise”. Am. J. Hypertens, vol. 21, no. 4, pp. 419-424.

[11] "Hybrid transceiver TR3000 (2008). Technical Data. RF Monolithics, Inc. pp.20.

[12] Wojcik, W., Vistak, M., Mykytyuk, Z., Politanskyi, R., Diskovskyi, I., Sushynskyi, O., Kremer, I., Prystay, T., Jaxylykova, A. and Shedreyeva, I. (2020) "Technical solutions and SPICE modelling of optical sensors". Przeglad Elektrotechniczny, vol. 96, no. 10, pp. 102-105. https://doi.org/: 10.15199/48.2020.10.18

[13] Encoder and Decoder Pairs. MC145026 - MC145028. (2005). "Freescale Semiconductor". Technical Data MC145026/D. Rev. 4. pp. 20. 


\title{
FUNCTIONAL DIAGNOSIS OF CARDIOVASCULAR SYSTEM CONDITION IN THE CONTEXT OF MODERN INFORMATION SYSTEMS
}

\author{
Z. Mykytyuk, G. Barylo, O. Blavt, I. Kremer, Yu. Kochurak \\ Lviv Polytechnik National University, 12, S. Bandery Str., Lviv, 79013, Ukraine
}

\begin{abstract}
The article is devoted to the problem of quality assurance and reliability of functional diagnostics of the cardiovascular system on the basis of heart rate control. A new approach to the implementation of diagnostic procedures in real time with the use of modern information systems as an opportunity to increase their efficiency. The multichannel system of registration of heart rate defined for continuous measurement of pulse in real time is presented. Before using in a multi-channel system of a modern information complex of electronic computing, using not only a few values of individual parameters, as well as in the study of the cardiovascular system will determine a wide range of diagnostic tasks with a high level of reliability. It is widely available that in this way a number of problem factors of the diagnostic process are used on the basis of integrated technology of many functional functions in a single multi-channel system, which allows to increase the efficiency of the functional diagnostic process, its efficiency and quality.
\end{abstract}

Key words: diagnostics; cardiovascular system; heart rate; multichannel system. 